\title{
Extreme hyponatremia with moderate metabolic acidosis during hysteroscopic myomectomy
} -A case report-

\author{
Youn Yi Jo ${ }^{1}$, Hyun Joo Jeon ${ }^{2}$, Eunkyeong $\mathrm{Choi}^{2}$, and Yong-Seon Choi ${ }^{2}$ \\ Department of Anesthesiology and Pain Medicine, ${ }^{1}$ Gachon University of Medicine and Science Gil Medical Center, Incheon, ${ }^{2}$ Yonsei \\ University College of Medicine, Seoul, Korea
}

Excess absorption of fluid distention media remains an unpredictable complication of operative hysteroscopy and may lead to lethal conditions. We report an extreme hyponatremia, caused by using an electrolyte-free $5: 1$ sorbitol/ mannitol solution as distention/irrigation fluid for hysteroscopic myomectomy. A 34-year-old female developed severe pulmonary edema and extreme hyponatremia $(83 \mathrm{mmol} / \mathrm{L})$ during transcervical endoscopic myomectomy. A brain computed tomography showed mild brain swelling without pontine myelinolysis. The patient almost fully recovered in two days. Meticulous attention should be paid to intraoperative massive absorption of fluid distention media, even during a simple hysteroscopic procedure. (Korean J Anesthesiol 2011; 60: 440-443)

Key Words: Hyponatremia, Hysteroscopy.

Hysteroscopy is a new technique of transcervical endoscopic surgery, which requires the insertion of a scope into the uterine cavity and the installation of a suitable distention medium for visualization of the endometrium. The medium and intrauterine pressure opens the potential space of the otherwise narrow uterine cavity. Hypotonic, nonconductive, low-viscosity fluids such as $5 \%$ mannitol, $3 \%$ sorbitol, and $1.5 \%$ glycine improve visualization when bleeding occurs, and they can be used in diagnostic as well as operative hysteroscopic media. These low viscosity fluids risk rapid fluid absorption, resulting in fluid overload, electrolyte imbalance, and variable concomitant side effects [1]. These side effects can also lead to death [2]. Although there have been reports of dilutional hyponatremia following hysteroscopy [1-3], there have been no cases presenting severe hyponatremia of less than $90 \mathrm{mmol} /$ $\mathrm{L}$ accompanied by metabolic acidosis. We report on a patient with an extreme hyponatremia caused by using an electrolytefree $5: 1$ sorbitol/mannitol solution as a distention medium for hysteroscopic myomectomy.

\section{Case Report}

A 34-year-old woman (height, $162 \mathrm{~cm}$; weight, $53 \mathrm{~kg}$ ) with menorrhagia was admitted for elective hysteroscopic

Received: November 19, 2010. Revised: January 3, 2011. Accepted: January 6, 2011.

Corresponding author: Yong-Seon Choi, M.D., Department of Anesthesiology and Pain Medicine, Yonsei University College of Medicine, 134, Shinchon-dong, Seodaemun-gu, Seoul 120-752, Korea. Tel: 82-2-2228-8518, Fax: 82-2-364-2951, E-mail: yschoi@yuhs.ac

(c) This is an open-access article distributed under the terms of the Creative Commons Attribution Non-Commercial License (http:// creativecommons.org/licenses/by-nc/3.0/), which permits unrestricted non-commercial use, distribution, and reproduction in any medium, provided the original work is properly cited. 
myomectomy of a $4.7 \times 4.5 \mathrm{~cm}$ submucosal benign fibroid adenoma. Three years before, she had undergone a large loop excision of the transformation zone of the uterine cervix due to carcinoma in situ. She had no other abnormal medical history and laboratory findings. She was premedicated with intramuscular injection of midazolam $2 \mathrm{mg}$ and glycopyrrolate $0.2 \mathrm{mg}$. Upon arrival at the operating room, standard monitoring devices were applied. Vital signs were blood pressure 121/70 $\mathrm{mmHg}$, heart rate 56 beats/min and pulseoxymetry revealed $99 \%$ of $\mathrm{SpO}_{2}$ before anesthetic induction. Anesthesia was induced with $1.5 \mathrm{mg} / \mathrm{kg}$ of propofol, and $1 \mu \mathrm{g} / \mathrm{kg}$ of remifentanil, and tracheal intubation was facilitated with 0.8 $\mathrm{mg} / \mathrm{kg}$ of rocuronium. The patient's lungs were ventilated with a tidal volume of $7-9 \mathrm{ml} / \mathrm{kg}$, I : E ratio of $1: 1.9$ at a respiratory rate of $8-12$ breaths/min in $50 \%$ oxygen with medical air to maintain normocarbia throughout the procedure. Anesthesia was maintained with continuous infusion of remifentanil (0.1$0.2 \mu \mathrm{g} / \mathrm{kg} / \mathrm{min}$ ) and sevoflurane (1.5-2.5\%). After the induction of anesthesia, $0.9 \%$ normal saline was infused at a rate of $4 \mathrm{ml} /$ $\mathrm{kg} / \mathrm{h}$. An esophageal temperature probe was monitored and the patient was kept warm using a forced-air warming system (BairHugger, Augustine-Medical, Eden Prairie, MN, USA) at $36^{\circ} \mathrm{C}$.

After lithotomy positioning for surgical hysteroscopy, electrolyte-free $5: 1$ sorbitol/mannitol solution was used as a distending solution. The solution was infused using a highpressure surgical irrigator (IrriGator; Biomedical Dynamics, Burnsville, Minnesota, USA) under pressures of 100-140 mmHg. The effluent distending solution was collected, and fluid balance was assessed continuously throughout the operation. At 40 minutes after the start of the procedure, 2 $\mathrm{L}$ of sorbitol/mannitol solution had been used, and effluent

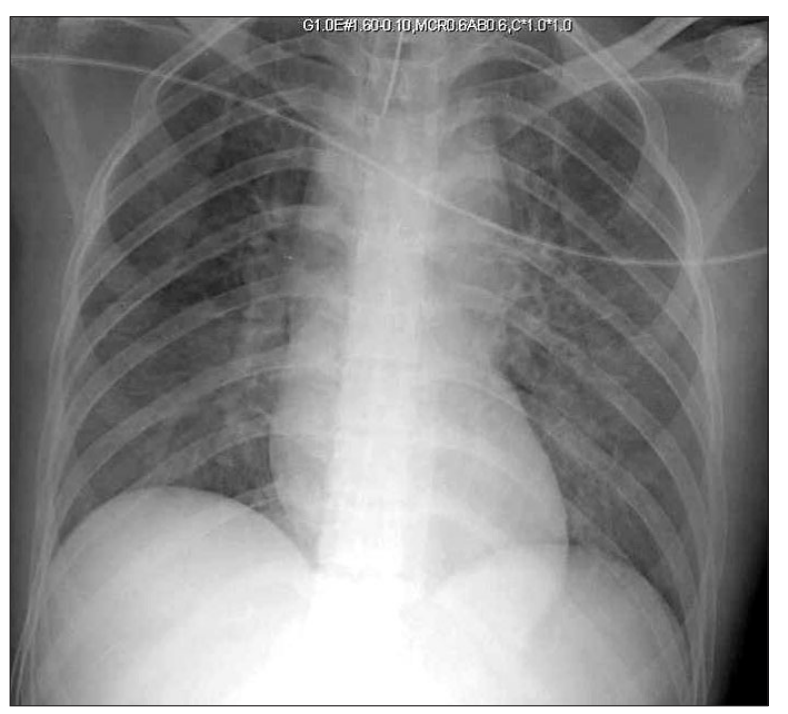

Fig. 1. Chest X-ray showing severe pulmonary edema. volume was not checked precisely due to a large amount of fluid leakage through the uterine cervix. During the procedure, the esophageal temperature gradually decreased from $36.5^{\circ} \mathrm{C}$ to $33^{\circ} \mathrm{C}$. At 50 minutes after the start of the procedure, $\mathrm{SpO}_{2}$ as measured by pulse-oximetry abruptly declined to $85 \%$, and endtidal $\mathrm{CO}_{2}\left(\mathrm{ETCO}_{2}\right)$ decreased to $22 \mathrm{mmHg}$. We inserted a $20 \mathrm{G}$ catheter to the left radial artery for continuous arterial pressure monitoring and blood sampling. The first arterial blood gas results were $\mathrm{pH}$ 7.264, $\mathrm{PaO}_{2} 151.7 \mathrm{mmHg}, \mathrm{PaCO}_{2} 31.7 \mathrm{mmHg}$, base excess $-12.7 \mathrm{mmol} / \mathrm{L}, \mathrm{SaO}_{2} 93.7 \%$ in $\mathrm{FiO}_{2}$ 1.0; other laboratory findings revealed sodium $83 \mathrm{mmol} / \mathrm{L}$, potassium 3.4 $\mathrm{mmol} / \mathrm{L}$, chloride $62 \mathrm{mmol} / \mathrm{L}$, hemoglobin $8.5 \mathrm{~g} / \mathrm{dl}$. The patient was immediately treated with $10 \mathrm{mg}$ of furosemide and infused with $3 \%$ saline at a rate of $60 \mathrm{ml} / \mathrm{hr}$. PEEP $5 \mathrm{cmH}_{2} \mathrm{O}$ was applied, $\mathrm{SpO}_{2}$ reached to $98-100 \%$ in $\mathrm{FiO}_{2}$ 1.0. The total procedure time was about 150 minutes and total infused intravenous fluid was crystalloid 1,160 ml, packed RBC 1 pint, and the total urine output was $3,600 \mathrm{ml}$. At the end of the procedure, arterial blood gas analysis showed $\mathrm{pH} 7.287, \mathrm{PaO}_{2} 143.7 \mathrm{mmHg}$, $\mathrm{PaCO}_{2} 29.5 \mathrm{mmHg}$, base excess $-10.6 \mathrm{mmol} / \mathrm{L}, \mathrm{SaO}_{2} 99.0 \%$ in $\mathrm{FiO}_{2}$ 0.5; other laboratory findings revealed sodium $92 \mathrm{mmol} /$ $\mathrm{L}$, potassium $4.7 \mathrm{mmol} / \mathrm{L}$, chloride $63 \mathrm{mmol} / \mathrm{L}$, hemoglobin $11.7 \mathrm{~g} / \mathrm{dl}$. Afterwards, she was cared for in the postanesthetic care unit for 40 minutes and her urine output was $1,600 \mathrm{ml}$, with $20 \mathrm{mg}$ furosemide. She was subsequently transferred to the intensive care unit (ICU) with stopping infusion of $3 \%$ saline. The patient's lungs were ventilated with synchronized intermittent mandatory ventilation, a tidal volume of $310 \mathrm{ml} /$ $\mathrm{kg}$, PEEP $8 \mathrm{cmH}_{2} \mathrm{O}$, pressure support $8 \mathrm{mmHg}$ at a respiratory rate of $8-12$ breaths/min in $40 \%$ oxygen. Chest auscultation revealed diffuse coarse crepitations over the whole lung field and the chest X-ray revealed severe pulmonary edema (Fig. 1). After admission to the ICU, urine output was maintained with $8-10 \mathrm{ml} / \mathrm{kg} / \mathrm{hr}$ with infusion of furosemide $(10 \mathrm{mg} / \mathrm{hr})$ for 16

Table 1. Electrolyte Data

\begin{tabular}{lcccc}
\hline & $\begin{array}{c}\text { Sodium } \\
(\mathrm{mmol} / \mathrm{L})\end{array}$ & $\begin{array}{c}\text { Potassium } \\
(\mathrm{mmol} / \mathrm{L})\end{array}$ & $\begin{array}{c}\text { Chloride } \\
(\mathrm{mmol} / \mathrm{L})\end{array}$ & $\begin{array}{c}\text { Osmolarity } \\
(\mathrm{mOsm} / \mathrm{kg})\end{array}$ \\
\hline $\begin{array}{l}\text { Preoperative values } \\
\begin{array}{l}\text { Values during the } \\
\text { procedure }\end{array}\end{array}$ & 140 & 4.4 & 102 & 288 \\
$\quad 50$ min & & & & \\
$\quad$ At the end & 83 & 4.6 & 62 & \\
$\begin{array}{l}\text { Postoperative values } \\
3 \text { hours }\end{array}$ & 92 & 3.6 & 63 & 203 \\
8 hours & 108 & 3.5 & 71 & \\
12 hours & 117 & 2.8 & 78 & 248 \\
18 hours & 118 & 3.2 & 80 & \\
24 hours & 121 & 2.8 & 80 & 250 \\
48 hours & 134 & 3.4 & 97 & 280 \\
\hline
\end{tabular}

Osmolality, $2 \times$ sodium + blood urea nitrogen $/ 2.8+$ glucose $/ 18$. 
hours, and serum sodium levels were recovered to $108 \mathrm{mmol} /$ L three hours later (Table 1). Brain computed tomography performed on the first postoperative day showed mild brain edema. At 15 hours after admission to the ICU, her mental status was alert without neuralgic sequalae, her vital signs were stable, and the pulmonary edema had improved. She was weaned from mechanical ventilation. The rest of the postoperative course was uneventful. She was transferred to the general ward on the second postoperative day and discharged on the fourth postoperative day. The patient remained asymptomatic during six months of follow-up with no neurologic complications.

\section{Discussion}

Hysteroscopic procedures have been increasingly used with several benefits when compared with traditional surgical procedures. Despite their increasing use, the absorption of fluid distention media can still cause unpredictable complications such as volume overload, dilutional hyponatremia, water intoxication, and cerebral edema [1-3]. Generally, serum sodium levels decrease by $10 \mathrm{mmol} / \mathrm{L}$ for every liter of hypotonic fluid absorption [4]. In a previous study of 101 patients who absorbed over $2 \mathrm{~L}$ of glycin solution during myoma resections, the patients did not develop volume overload, and their recovery was usually uneventful within 12 hours [5]. However, absorption of less than $2 \mathrm{~L}$ of distention medium could cause death induced by hyponatremia ( $98 \mathrm{mmol} / \mathrm{L}$ ) and cerebral edema [3]. In our case, the patient experienced extreme hyponatremia (83 $\mathrm{mmol} / \mathrm{L}$ ) accompanied by metabolic acidosis due to absorption of the distention medium, resulting in pulmonary edema and brain swelling, with absorption of less than $2 \mathrm{~L}$ of distention fluid.

Hyponatremia is one of the most common electrolyte disturbances encountered by anesthesiologist, and sometimes it can lead to permanent or lethal complications. Dilutional hyponatremia combined with water intoxication can cause fatal cerebral edema and lead to death. It is thought that the free water of distention medium readily traverses cellular membranes and the blood brain barrier, moving easily between the intravascular, extracellular, and intracellular spaces as an osmotic gap between areas equilibrating extra and intracellular osmolality. Although extreme hyponatremia is associated with convulsions and coma, the classic central nerve system signs are mainly caused by the accompanying acute serum hypoosmolality [6]. In our case, the patient's mental status was fully recovered without neurologic complications about 17 hours after the development of severe hyponatremia. Although we did not evaluate the value of measured serum osmolality in this patient, the sorbitol and mannitol in the distention medium, which are restricted to the extracellular fluids and draw water from the central compartment, may cause extremely reduced serum sodium levels while relatively maintaining the serum osmolality $[7,8]$. The relatively maintained serum osmolality may be associated with the rapid recovery and lack of neuralgic sequalae in this patient. Although the amount of distention fluid absorbed seems to be dependent on the duration of the procedure and the pressure of surgical irrigator, the absorption volume of distention medium measured by the surgical irrigator does not necessarily reflect changes in serum sodium and osmolality. Therefore, the measurement, not calculation, of serum osmolality, may predict the clinical course.

In previous cases, respiratory acidosis induced by hypercarbia was accompanied by pulmonary edema $[2,3]$. Hypercarbia may induce peripheral arteriolar dilatation and lead to the increased absorption of fluid distention medium. However, in our case, moderate metabolic acidosis was observed with decreased serum bicarbonate concentration and this was resolved after correction of hyonatremia. Dilutional acidosis occurs when the plasma bicarbonate concentration is decreased by extracellular volume expansion. However, the total amount of extracellular bicarbonate did not decrease with rapid volume expansion but simply decreased in concentration [9]. In a previous animal study, with normal renal function, acute volume expansion caused increased renal bicarbonate wasting. Bicarbonate reabsorption decreased due to increased sodium diuresis and decreased reabsorption of solute in the proximal tubule. Therefore, patients with normal renal function may have potential for worsening dilutional acidosis with acute volume expansion [10].

Rapid correction of hyponatremia can also lead to neurologic disorder, so it was suggested that the correction not exceed $25 \mathrm{mmol} / \mathrm{L}$ in 48 hours [11]. Neurologic disorders such as extrapontine and pontine myelinolysis related with rapid correction have usually been known to develop in chronic hyponatremic patients. In our case, the serum sodium level was rapidly corrected with only $3 \%$ saline at a rate of $60 \mathrm{ml} / \mathrm{hr}$ for 140 minutes and a large amount of urine output. In the healthy system, osmoreceptors in the hypothalmus sense the diffusion of water into or out of receptor cells caused by changes in serum osmolality. In response, the hypothalamus directs the pituitary to increase or decrease the release of vasopressin from the posterior pituitary [12]. In this case, although furosemide was used, fluid overload may have caused a decrease in vasopressin release, leading to dieresis and rapid recovery of serum sodium levels.

The anesthetic method for endoscopic hysteroscopy is controversial. In a previous study, a significantly lower amount of distention fluid was absorbed during hysteroscopy with general anesthesia rather than epidural anesthesia [13]. However, general anesthesia could mask early signs of 
hyponatremia and water intoxication such as bradycardia, hypertension, headache, nausea, and mental status change [14]. In our patient who had general anesthesia, we did not detect water intoxication and hyponatremia until pulmonary edema developed. Therefore, especially in the cases where general anesthesia is used during hysteroscopy, intraoperative fluid balance should be maintained and the possibility of water intoxication should be considered when saturation and capnogram abruptly decrease.

In conclusion, this case shows the risk of extreme hyponatremia with moderate metabolic acidosis caused by distention medium absorption during minimally invasive hysteroscopy. Early detection and prompt management of massive absorption of fluid distention medium is important for patient recovery without neurologic complications.

\section{References}

1. Schäfer M, Von Ungern-Sternberg BS, Wight E, Schneider MC. Isotonic fluid absorption during hysteroscopy resulting in severe hyperchloremic acidosis. Anesthesiology 2005; 103: 203-4.

2. Katz Y, Moscovici R, Prego G, Merzel Y, Kniznik D, Lev A. A death following hysteroscopic myomectomy. Gynaecol Endosc 2001; 10: 367-70.

3. Kim HH, Hwang JY, Jeon YT, Hwan JW, Do SH, Na HS. Developed hyponatremia during hysteroscopic myomectomy: A case report. Korean J Anesthesiol 2009; 57: 629-32.

4. Isaacson KB. Complications of hysteroscopy. Obstet Gynecol Clin North Am 1999; 26: 39-51.

5. Istre O, Skajaa K, Schjoensby AP, Forman A. Changes in serum electrolytes after transcervical resection of endometrium and submucous fibroids with use of glycine $1.5 \%$ for uterine irrigation. Obstet Gynecol 1992; 80: 218-22.

6. Witz CA, Silverberg KM, Burns WN, Schenken RS, Olive DL. Complications associated with the absoption of hysteroscopic fluid media. Fertil Steril 1993; 60: 745-56.

7. Norlén H, Allgén LG, Wicksell B. Sorbitol concentrations in plasma in connection with transurethral resection of the prostate using sorbitol solution as an irrigating fluid. Scand J Urol Nephrol 1986; 20: 9-17.

8. Norlén H, Allgén LG, Wicksell B. Mannitol concentrations in blood plasma in connection with transurethral resection of the prostate using mannitol solution as an irrigating fluid. Scand J Urol Nephrol 1986; 20: 119-26.

9. Hamill-Ruth RJ. Dilutinal acidosis: a matter of perspective. Crit Care Med 1999; 27: 2296-7.

10. Garella S, Tzamaloukas AH, Chazan JA. Effect of isotonic volume expansion on extracellular bicarbonate stores in normal dogs. Am J Physiol 1973; 225: 628-36.

11. Ayus JC, Krothapalli RK, Arieff AI. Treatment of symptomatic hyponatremia and its relation to brain damage. A prospective study. N Engl J Med 1987; 317: 1190-5.

12. Verbalis JG, Goldsmith SR, Greenberg A, Schrier RW, Sterns RH. Hyponatremia treatment guidelines 2007: expert panel recommendation. Am J Med 2007; 120: S1-21.

13. Goldenberg M, Cohen SB, Etchin A, Mashiach S, Seidman DS. A randomized prospective comparative study of general versus epidural anesthesia for transcervical hyeteroscopic endometrial resection. Am J Obstet Gynecol 2001; 184: 273-6.

14. Ananthanarayan C, Paek W, Rolbin SH, Dhanidina K. Hysteroscopy and anaesthesia. Can J Anaesth 1996; 43: 56-64. 